\title{
Steroid Hormone and Antihormone Induced Changes in the Pineal and Adrenocortical Karyomorphology and Cell Proliferation in Mice (Mus Musculus )
}

\author{
Rajasree Bandyopadhyay \\ Ph.D. of Department of Zoology, University of Calcutta \\ 35, Ballygunge Circular Road, Kolkata 700 019, India \\ Moumita DasGupta \\ M.Sc. of Department of Zoology, University of Calcutta \\ 35, Ballygunge Circular Road, Kolkata 700 019, India \\ Subrata Chakraborty (Corresponding author) \\ Professor, Pineal Research Unit, Department of Zoology, University of Calcutta \\ 35, Ballygunge Circular Road, Kolkata 700 019, India \\ E-mail: subratachakraborty2000@yahoo.co.in
}

\begin{abstract}
Hormone-induced reponsiveness of the pineal and adrenal glands was studied in post-pubertal male mice (Mus musculus). The influence of steroid hormones (estradiol and testosterone) and non-steroidal antihormones (tamoxifen and flutamide) on pineal and adrenal karyomorphology and cell proliferation activity was analyzed. Estradiol was injected at a dose of $5 \mu \mathrm{g}$, testosterone $100 \mu \mathrm{g}$, tamoxifen $500 \mu \mathrm{g}$ and flutamide $2 \mathrm{mg}$ per $100 \mathrm{~g}$ body weight administered intramuscularly in all cases for ten consecutive days. Control mice were similarly injected with $0.3 \mathrm{ml}$ of peanut oil vehicle intramuscularly for the same duration. The results indicated that, except testosterone, all other treatments with estradiol, tamoxifen and flutamide caused significant hyperactivity in both the pineal and the adrenal glands, associated with significantly increased cell proliferation activity. On the contrary, testosterone administration was inhibitory to pineal - adrenal karyometric and mitotic incidence values. It was concluded that in male post-pubertal mice both pineal and adrenal glands show antagonistic response towards estradiol and testosterone administration. Although tamoxifen showed estrogen agonistic behaviour, flutamide conversely induced pineal and adrenal cytophysiological stimulation. Such stimulatory response was antagonistic to the inhibitory response shown by pineal and adrenal karyomorphology and cell proliferation following testosterone administration.
\end{abstract}

Keyword: Pineal, Adrenal, Karyomorphology, Cell proliferation, Steroids, Antihormones

\section{Introduction}

Studies relating cell morphology and dynamics responsiveness of both the pineal and adrenal gland through administration of sex steroids and antihormones awaits systematic investigation. It may be construed that understanding the relationship between pineal and adrenal gland is incomplete without studying the pineal-adrenocortical relationship in response to diversely altered steroid milieu.

Studies conducted by Cardinali et al. (1975) reveal that the pineal gland acts as a target organ for both estrogens and androgens. Findings indicate that sex steroids attaining the pinealocytes through systemic administration act as an active modulator of pineal metabolic activity and change in the rate of synthesis of pineal hormones in mammals (Clementi et al. 1965; Cardinali et al; Karasek et al. 1976a,b; Cardinali \& Vacas 1978; Hernandez et al. 1990). It was later suggested that gonadal steroids modulate melatonin secretion by activating multiple receptors in the pineal gland including modulation of NAT, N-acetyl transferase (Luboshitzky et al. 1997; Okatani et al. 1997; 1998a, b).

While estradiol is found to increase the nuclear diameters of pinealocytes in juvenile male rats, it fails to have any effect on pineal cytology in juvenile female rats. This hormone however induced mitosis in pinealocytes of 
juvenile female rats (Sahu \& Chakraborty 1986). Similarly earlier reports from bandicoot rats show pineal stimulation by estradiol (Chakraborty et al. 1981). Similarly androgen has also been found to influence pineal activity. Testosterone is actively taken up by the pineal cell in vivo and in vitro (Cardinali et al. 1974b). Testosterone has also been found to cause inhibition of pineal cellular synthesis (Armer 1976), whereas it stimulates melatonin synthesis activity in the pineal gland of male rats (Urry et al. 1976), but it appears to be non-stimulatory, if not inhibitory, to the pineal function in the wild male rodent, Bandicoota bengalensis (Chakraborty et al. 1981). Experimental results suggest that influence of androgens on pineal glands are dependent on the dose of testosterone, it may be either stimulated at low dose (Cardinali et al. 1975) or inhibited at higher doses (Nagle et al. 1974; Cardinali et al. 1987).

Similar accumulated evidence shows that adrenal cortex secretory function is influenced by gonads and experimental alteration in gonadal status through sex hormone administration. Both estrogen and androgen has long been found to influence adrenocortical function (Chester Jones 1957). Studies on the effects of natural and synthetic estrogen, in almost all the cases, reveal a markedly stimulating influence of these sex steroids on adrenal cortex as reported in mice, rats and guinea pigs (Tepperman et al. 1943). Alternate experimental studies show that male rats treated with estrogen show signs of both inhibition (Mckerns et al. 1958; Troop \& Possanza, 1962; Kitay, 1963a) and stimulation (Lluarado et al. 1962; Kitay 1963c) of adrenal gland. More recently it was documented that chronic administration of stilbesterol and estradiol benzoate increases cellular and nuclear volume of zona fasciculata and reticularis of male rats (Nussdorfer 1986).

Besides steroid hormones used to study endocrinological aspects, a number of non steroidal hormones that antagonize the action of a particular hormone has been developed. Studies have revealed that non steroidal antihormones like tamoxifen (an antiestrogen) and flutamide (an antiandrogen) have the capability to bind with sex steroid receptors present in the tissue. Tamoxifen acts as a pure estrogen antagonist at a low dose to full estrogen agonist at a higher dose (Rastogi and Chieffi 1975). Unlike in rats, tamoxifen administered to mice acts as a full estrogen agonist (Furr et al. 1979) and also causes atrophy of steroid sensitive glands (Harper \& Walpole 1967).

It is evident that these non steroidal antihormones have the capability to bind with sex steroid receptors of the target organ and alter their activity. Hence it was speculated that a study of the effect of these antihormones, along with steroid modulation of steroid-sensitive glands (e.g. pineal and adrenocortical activity), will effectively provide first time evidence of their influence on cell morphology, activity, and the nature of cell proliferation in the pineal and adrenal cortex of male post-pubertal mice.

\section{Material and methods}

The pineal adrenocortical relationship was manipulated through administration of sex steroid hormones and antihormones in post-pubertal male mice following acclimatization to the laboratory conditions for three days. The post-pubertal male mice (Charles Foster Strain) weighing between 15-18 g were used for the current study. A total of thirty-five post-pubertal male mice were used for the experiment.

\subsection{Control}

Post-pubertal male mice $(\mathrm{N}=7)$ received $0.3 \mathrm{ml}$ of peanut oil vehicle daily during the entire experimental schedule of ten consecutive days.

\subsection{Estradiol treatement}

Estradiol valerate (Progynon Depot., Schering AG, Germany) was diluted in peanut oil vehicle and administered to post-pubertal male mice ( $\mathrm{N}=7$ ) daily at a dose of $5 \mu \mathrm{g} / 100$ gm body weight (Chakraborty et al. 1981).

\subsection{Tamoxifen treatment}

Postpubertal male mice $(\mathrm{N}=7)$ daily received antiestrogen tamoxifen (Tamoxifen citrate, Lyka Labs Ltd, India) in peanut oil vehicle at a dose of $500 \mu \mathrm{g} / 100 \mathrm{gm}$ body weight (Rastogi \& Chieffi 1975).

\subsection{Testosterone treatment}

Testosterone enanthate (Testosterone Depot, Schering AG, Germany) diluted in peanut oil vehicle was injected daily to each post-pubertal male mouse $(\mathrm{N}=7)$ at a dose of $100 \mu \mathrm{g} / 100 \mathrm{gm}$ body weight (Chakraborty et al. 1981).

\subsection{Flutamide treatment}

Post-pubertal male mice $(\mathrm{N}=7)$ received flutamide (Flutide, Samarth Pharmaceuticals, India) in peanut oil vehicle daily at a dose of $2 \mathrm{mg} / 100 \mathrm{gm}$ body weight (Gromoll et al. 1993). 
All the injections were given intramuscularly in alternate thigh muscle daily for ten consecutive days. The mice were housed in photoperiodic chambers fitted with fluorescent light and an exhaust fan. The daily photoperiod 12L: 12D lights on at 6.00 hours and off at 18.00 hours were controlled by timer switches (Surrey, U.K.). The animals were supplied with mice pellets and water ad libitum.

The experimental animals were maintained and used as per guidelines of Institutional Animal Ethics Committee, University of Calcutta accredited by the committee for the Purpose of Control and Supervision of Experiments on Animals (CPCSEA), Ministry of Environment and Forest, Govt. of India.

On the day of autopsy, i.e., on the eleventh day of experiment, the animals were injected with colchicine $(0.1 \mathrm{mg}$ / 100 gm body weight) to obtain metaphase arrested mitotic cells. The animals were killed by an overdose of ether six hours after colchicine treatment (Quay \& Levine 1957; Maiti \& Chakraborty 1980; Chakraborty \& Maiti 1981) approximately twenty-four hours after the administration of last dose of the drug. Both the pineal and adrenal glands were excised out, fixed in Bouin's fixative and routine processes required for histological study were performed.

Extensive studies have shown that in pineal and adrenal glands, an active phase is characterized by an increased nuclear size, indicating synthesis activity, whereas inhibition of pineal and adrenal is characterized by a decreased nuclear size. In all cases, pineal (Quay 1976; Chakraborty 1981, 1993, 1994; Chakraborty \& Maiti 1981; Chakraborty et al. 1981, 1982, 1994; Maiti \& Chakraborty 1982; Diehl et al. 1984; Sahu \& Chakraborty 1983, 1986; Chaudhuri \& Maiti 1989; Hira et al. 1989; Martinez Soriano et al. 1990; Bandyopadhyay et al. 2000) and adrenal (Miller 1954; Maitra \& Chakraborty 1983; Maitra 1987; Chakraborty 1994) cytological studies were made from mid-sagittal paraffin section of $5 \mu \mathrm{m}$ thickness, stained with haematoxylin-eosin and observed under oil immersion (15 ocular x 100 objective). Only the right adrenal glands were used for histological studies.

\subsection{Karyomorphology}

Morphometric evaluation of at least 150 oval to round nuclei were made from each of the five randomly selected mid-sagittal sections per specimen. Furthermore, nuclear diameters of the adrenal cortex were randomly measured zone wise. In all cases, nuclei were measured under oil immersion using 15 ocular x 100 objective lenses along with ocular micrometer scale. All the ocular diameter values were then converted to $\mu \mathrm{m}$ values. Individual value of the specimen was the mean values of the five sectional measurements. The final mean values of the experimental group were computed from these individual measurements.

\subsection{Karyodynamics}

The number of colchicine arrested metaphase cells or the mitotic figures have been considered as an index for cell proliferative activity (Quay \& Levine 1957; Maiti \& Chakraborty 1980; Chakraborty \& Maiti 1981; Maiti et al 1982). In the present work, the numbers of mitotic figures found in the pineal and adrenal cortex were recorded from each section under oil immersion ( 15 ocular x 100 objective). The number of metaphase cells per hundred cells was counted from five randomly selected mid-sagittal sections per animal, and these counts were expressed as mitotic percentage (M\%) for the morphometric analysis.

\subsection{Statistical analysis}

Values were presented as the means of the observations following experimental manipulation. All the karyomorphological and karyodynamic values for the control and treated mice were compared and the levels of significance were statistically evaluated by student's ' $t$ ' test (Winer 1971) and ANOVA (Microcal Origin, Version 4.00).

\section{Results}

\subsection{Pineal Gland}

\subsubsection{Control oil vehicle}

Conventional staining of histological sections of the pineal gland reveals the gland as a solid, homogenous, parenchymatous mass, comprising of pinealocytes of various sizes, with round to oval nuclei (Fig 1).

\subsubsection{Estradiol treatment}

Estradiol injection in post-pubertal male mice produced a significant change in the glandular parenchyma, indicating hyperactivity of the gland. The cells showed secretory appearance, revealed by a pinealocyte nucleus, containing single distinct nucleolus and less dense chromatin material. The pinealocyte nuclei exhibited an increase in diameter $(\mathrm{p}<0.001)$ along with a notable hyperplasia $(\mathrm{p}<0.001)$ (Figs 2,11 and 12). 


\subsubsection{Tamoxifen treatment}

Administration of tamoxifen induced an estrogen agonist activity in the pineal cells. Histological observations revealed the presence of oval nuclei with prominent nucleolus and loose, indistinct chromatin materials (Fig 3). This treatment manifested significant increase in nuclear diameter $(\mathrm{p}<0.001)$ and mitotic incidence $(\mathrm{p}<0.001$, Figs 3, 11 and 12).

\subsubsection{Testosterone treatment}

A significant atrophy of the pineal gland of post-pubertal male mice was observed following testosterone treatment. The pineal parenchyma exhibited oval nuclei with indistinct nucleolus and granular chromatin material (Fig 4). It induced a perceptible decrease in the nuclear size $(\mathrm{p}<0.001)$ and mitotic incidence $(\mathrm{p}<0.05$, Figs 4, 11 and 12).

\subsubsection{Flutamide treatment}

Antiandrogen, flutamide, acted as a true androgen antagonist, inducing hyperactivity of the pineal gland. The pinealocyte nuclei showed the presence of a prominent nucleolus and loose chromatin material (Fig 5). This alteration in the glandular activity was evident from the increased nuclear diameter $(p<0.05$, Fig 11) and cell proliferative activity $(\mathrm{p}<0.001$, Fig 12$)$.

Results from one-way ANOVA of pinealocyte nuclear diameters $[\mathrm{F}(4,30)=123.12, \mathrm{p}<0.001]$ and mitotic incidence $[\mathrm{F}(4,30)=13.06, \mathrm{p}<0.001]$ in groups administered with oil vehicle (control), estradiol, tamoxifen, testosterone and flutamide reveal significant differences in the mean values and thus indicating significant changes between the experimental groups.

\subsection{Adrenal cortex}

\subsubsection{Control oil vehicle}

Microscopic anatomy of the adrenal cortex in post-pubertal male mice comprised of three distinct zones, namely, zona glomerulosa, zona fasciculata and zona reticularis, that exhibited nuclei with prominent nucleolus and granular chromatin material. Mitotic figures are shown in Fig 6.

\subsubsection{Estradiol treatment}

Chronic estradiol administration produced a convincing hyperactivity of the adrenal cortex. The cortical nuclei exhibited distinct large nucleolus and not very distinct chromatin material. The glomerulosa zone showed the presence of definitely oriented cells with distinct, large nuclei ( $p<0.001$, Fig 7$)$. Similarly, the cords of polygonal cells of both zona fasciculata and zona reticularis also showed significant compactness along with increased nuclear diameter $(\mathrm{p}<0.001$, Figs $7 \& 13)$. This treatment was also found to induce a notable increase in mitotic incidence ( $\mathrm{p}<0.001$, Fig 14).

\subsubsection{Tamoxifen treatment}

Administration of tamoxifen manifested significant hyper-activity of the adrenal cortex, followed by appearance of nucleus with prominent, large nucleolus and less compact chromatin material (Fig 8). Cells of the glomerular zone contained large oval nuclei ( $<<0.05$, Fig 13) as also observed in the cells of the fasciculata ( $p<0.01$, Fig 13) and the reticularis $(p<0.01$, Fig 13) zones of the adrenal cortex. This change was accompanied by significant hyperplasia ( $<<0.05$, Fig 14). It was noted that all the three zones exhibited specific orientation and the cells of zona fasciculata and reticularis appeared as compact cords of polyhedral cells.

\subsubsection{Testosterone treatment}

Testosterone treatment induced drastic atrophic changes in the histological aspect of the adrenal cortex in post-pubertal male mice. It was noted that the nuclei of each zone possessed indistinct nucleolus and granular chromatin material (Fig 9). The cells of glomerulosa lacked specific orientation while the cells of both fascicular and reticularis zones appeared as loose cords. This atrophy was evident from the decrease in nuclear size in zona glomerulosa ( $<<0.001$, Fig 13), zona fasciculate $(0<0.001$, Fig 13) and zona reticularis $(p<0.001$, Fig 13$)$. This alteration was followed by a concomitant hypoplasia ( $\mathrm{p}<0.001$, Fig 14$)$.

\subsubsection{Flutamide treatment}

Flutamide, an antiandrogen acted as a true androgen antagonist as revealed by the hypertrophic characteristic of the adrenal cortex. Histological studies revealed that the cortical cells of all three zones possessed specific arrangement and the cords of cells of fasciculata and reticularis zones appeared more compact. The nuclei contained prominent, large nucleolus and loose chromatin material (Fig 10). This change was indicated by 
increased nuclear size of zona glomerulosa cells ( $p<0.01$, Fig 13), zona fasciculata cells $(p<0.001$, Fig 13) and zona reticularis cells ( $p<0.01$, Fig 13) along with a notable increase in mitotic incidence $(p<0.001$, Fig 14$)$.

Results from one way ANOVA for adrenocortical nuclear diameters $[F(4,30)=109.25, p<0.001$ for zona glomerulosa; $\mathrm{F}(4,30)-95.16, \mathrm{p}<0.001$ for zona fasciculata and $\mathrm{F}(4,30)=155.92, \mathrm{p}<0.001$ for zona reticularis] and mitotic percentage $[\mathrm{F}(4,30)=18.76, \mathrm{p}<0.001]$ from groups of animal treated with either oil vehicle (control), estradiol, tamoxifen, testosterone or flutamide reveal significant variations in the mean values and hence indicate significant changes between the experimental groups.

\section{Discussion}

Current quantitative morphology, as evident from karyometric values and associated histological studies, indicate that both pineal and adrenocortical cytology show differential response to altered steroid milieu, induced by exogenous administration of sex steroids and non-steroidal antihormones.

It is interesting to note that the cytophysiological changes indicated by karyomorphological alterations in the pineal gland (Quay 1976; Chakraborty et al. 1981; Diehl et al. 1984; Sahu \& Chakraborty 1983, 1986; Hira et al. 1989; Martinez Soriano et al. 1990) and adrenal cortex (Miller 1954) in mammals provide significant indices of the nature of activities of these glands.

Evidence reveals that the pineal gland influences the gonadal activities and that a reciprocal effect of the gonads on the pineal function also exists (Wurtman et al. 1965) indicating that our present study is in confirmation with earlier suggestion that the pineal gland acts as a target organ for the sex steroids (Cardinali et al. 1975). Both estrogen and testosterone are taken up by the pineal gland and metabolized within the pinealocytes (Nagle et al. 1972; Cardinali et al. 1974b) which in turn influences the biosynthetic pathway of the gland.

It is apparent from the present study that pineal cellular response to estradiol and testosterone in postpubertal male mice are inverse of each other. The pineal gland reacts to estradiol input by becoming significantly hyperactive, in so far as the synthetic phase of the pineal parenchymal cells is concerned. This is evident from the augmented pinealocyte nuclear size and mitotic incidence. Conversely, exogenously administered testosterone initiated the inhibition of the cellular synthetic process in the gland, indicated by reduced nuclear diameter and the pineal cells' proliferative activity.

The current observations are supported by studies that show exogenous estradiol to induce hyperactivity of the pineal gland (Clementi et al. 1965) and thereby resulting in the stimulation of the pineal cellular synthetic process in both male adult (Chakraborty et al. 1981) and juvenile (Sahu \& Chakraborty 1986) rats. This hormone also induced mitosis in pinealocytes of juvenile rats (Sahu \& Chakraborty 1986).

Biochemical analysis, authenticating the histological findings, reveals that the female sex steroids augment the pineal content of DNA, RNA and proteins in mammals (Nir et al. 1970). In female rats hydroxyindole-O-methyltransferase (HIOMT) activity is either enhanced (Houssay \& Barcelo 1972) or depressed (Wurtman et al. 1965) by lower or higher dose of estrogen respectively. Other in vitro and in vivo experiments also show that estradiol augments HIOMT (Mizobe \& Furokawa 1976) melatonin synthesis (Cardinali et al. 1981) resulting in an increase in pineal melatonin content in both rats and guinea pigs (Cardinali et al. 1987). However, in contradiction, recent publications suggest that estrogen modulates both nocturnal pineal melatonin synthesis and adenylate activity in peripubertal female rats, indicating inhibition of the pineal activity (Okatani et al. 1997, 1998a, b).

Male sex hormone, androgen, induces inhibition of the pineal cellular synthetic activity in hamsters (Armer 1976) while it fails to influence the gland's function in wild male rats (Chakraborty et al. 1981). In vitro experiments in rats reveal that testosterone reduces the melatonin content of the pineal gland (Cardinali et al. 1987) thus supporting the present results which imply that the male sex steroid acts as an inhibitor of the pineal gland activity. Similarly, large dose of androgen inhibits HIOMT activity (Nagle et al. 1974, Cardinali 1981) while a small dose of this hormone augments the enzyme activity (Cardinali et al. 1975; Cardinali 1981).

Our current investigation corroborates earlier suggestion that the pineal gland acts as the target organ for both estrogen and testosterone in mammals (Cardinali et al. 1975). From these studies it was evident that the sex steroids attaining the pinealocytes through systemic circulation act as an active modulator of pineal metabolic function and thereby alter the rate of synthesis of pineal melatonin in mammals (Clementi et al. 1965; Nagle et al. 1972; Cardinali et al. 1974b, 1975; Karasek et al. 1976a,b; Cardinali \& Vacas 1978; Hernandez et al. 1990).

Earlier experiments elucidate that both natural and synthetic estrogens have a stimulatory influence on the adrenal size in mammals, particularly in mice, rats and guinea pigs (Tepperman et al. 1943). However, exceptions to these findings indicate that estrogen reduces the adrenal size in immature rats (Clausen \& 
Freudenberger 1939; Seyle \& Albert 1942). Thus, the results indicate that estrogen either inhibits (Mc Kerns et al. 1958; Troop \& Possanza 1962; Kitay 1963a) or stimulates (Lluarado et al. 1962; Kitay 1963c) the adrenal glands.

The present study supports the idea that the adrenocortical cellular morphology can be influenced by exogenously administered estradiol in postpubertal male mice. Estradiol valerate administration in postpubertal male mice increase the nuclear diameter in all the three zones - zona glomerulosa, fasciculata and reticularis of the adrenal cortex with further intensification of the overall picture of cortical hypertrophy and enhanced mitotic percentage. It may be mentioned here that our findings also corroborated earlier experiments where chronic administration of stilbestrol and estradiol benzoate increased cellular and nuclear volume in the zona fasiculata and retucularis ( $c f$ Nussdorfer 1986).

Besides the female sex steroids, male sex hormone, androgen, influences the adrenocortical functions (Kime et al. 1980). Previous experimental observations elucidate that testosterone either produces atrophy of the adrenal glands or fails to induce any alteration in the cortical activity (Nathanson \& Brues 1941).

The present investigation reveals that exogenous testosterone induced an inhibitory effect on the adrenocortical activity as reflected by the significant reduction in the nuclear size in all the three zones of adrenal cortex along with a concomitant decrease in mitotic incidence. These results are authenticated by earlier biochemical reports where higher doses of testosterone depress both corticosterone production by adrenal slices (Kitay et al. 1966) and adrenal steroid content (Roy \& Mahesh 1964). Furthermore, cortisol synthesis in bovine adrenocortical cells is diminished in the presence of testosterone and dihydrotestosterone (Issacson et al. 1993). However, these observations are in conflict with previous reports, where low doses of testosterone enhanced adrenal slice performance (Kitay 1963b).

The experiments conducted on postpubertal male mice have shown that non-steroidal antiestrogen, tamoxifen induces significant hypertrophy of both pineal gland and adrenal cortex as indicated by the increased pinealocyte and adrenocortical nuclear size. These changes are accompanied with enhanced mitosis in the pineal gland and adrenal cortex. The hyperactivity of both pineal and adrenal cortex induced by tamoxifen is similar to the results obtained following estradiol administration in postpubertal male mice. This estrogen agonist activity of tamoxifen is supported by earlier reports where tamoxifen administered at high dose produces results similar to estrogen treatment (Rastogi \& Chieffi 1975). Investigators believe that tamoxifen binds with specific sex-steroid receptor sites of the tissues and thereby act either as a steroid agonist or antagonist (Rastogi \& Chieffi 1975, Koseki et al 1977).

Similarly, non-steroidal antihormones, flutamide used in the present experimental study, enhance the pinealocyte nuclear size, leading to hyperactivation of the pineal gland. This experimental observation is supported by studies showing that administration of antiandrogens - cyproterone and cyproterone acetate -- increased the pineal synthetic activity (Gusek 1971, 1976).

Simultaneously, exogenous flutamide seemed to stimulate adrenocotical function. This is reflected in the occurrence of large-sized nuclei in the entire adrenocortical zones, namely glomerulosa, fasciculata and reticularis unlike in previous studies where cyproterone acetone induced atrophy of zona fasciculata and reticularis in adrenal cortex of both juvenile and adult rats (Stadtler \& Langner 1985). In another experiment, flutamide failed to induce any alteration in adrenal steroidogenesis in guinea pigs (Belanger et al. 1992).

To summarize our findings it may be stated that estradiol and testosterone influence on pineal and adrenocortical relationship is in effect opposite in nature, at the dose and duration applied to male post-pubertal mice in our experiments. While estradiol was stimulatory to pineal and adrenocortical karyomorphology and cell proliferation, testosterone on the contrary was inhibitory to both pineal and adrenocortical function as substantiated by hypoactivity and hypoplasia of cell activities. Influence of non-steroidal antihormones showed disparity. Effect of tamoxifen was that of an estradiol agonist, inducing significant hypertrophy and hyperplasia of both pineal and adrenal cortical cells. Flutamide, on the other hand, acted as a potent antiandrogen at the dose and duration employed, and unlike testosterone, it caused pineal and adrenocortical stimulation as demonstrated by enhanced nuclear diameter and cell proliferation of pineal and adrenal cortex in male mice.

\section{Acknowledgement}

Rajasree Bandyopadhyay wishes to thank CSIR, New Delhi for the award of Senior Research Fellowship.

\section{References}

Armer, A. A. (1976). The effects of castration and testosterone on the fine structure of hamster pinealocytes. Anat. Rec., 184, 346 (Abstract). 
Bandyopadhyay, R., Ganguli, S., \& Chakraborty, S. (2000). Inverse changes in the pineal and adrenocortical morphology induced by dehydration stress was independent of extreme long and short daily photoperiod in neonatal chicks (Gallus domesticus). Proc. Zool. Soc., 53, 4-14.

Belanger, B., Caron, S., Boudou, P., Fiet, J., \& Belanger, A. (1992). Adrenal steroidogenesis in the guineapig : effects of androgens. Steroids, 57, 76-81.

Cardinali D. P. (1981). Hormone effects on pineal gland. In R. J. Reiter (Ed.), The Pineal Gland, Vol. 1, pp. 243-272). Florida: CRC Press, Boca Raton.

Cardinali, D P., Nagle, C. A., \& Rosner, J. M. (1974a). Effects of estradiol on melatonin and protein synthesis in the rat pineal organ. Horm. Res., 5, 304-310.

Cardinali, D. P., Nagle, C. A., \& Rosner, J. M. (1974b). Metabolic fate of androgens in the pineal organ: uptake binding to cytoplasmic proteins and conversion of testosterone into $5 \alpha$-reductase metabolites. Endocrinology, 95, 179-187.

Cardinali, D. P., Nagle, C. A., \& Rosner J. M. (1975). Gonadal steroids as modulators of the function of the pineal gland. Gen. Comp. Endocrinol., 26, 50-58.

Cardinali, D. P., \& Vacas, M. I. (1978). Feedback control of pineal function by reproductive hormones - a neuroendocrine paradigm. J. Neural Transm. Suppl., 13, 175-201.

Cardinali, D. P., Vacas, M. I., \& Ritla, M. N. (1981). A biphasic effect of estradiol on serotonin metabolism in rat pineal organ cultures. Experimentia, 37, 203-204.

Cardinali, D. P., Vacas, M. I., Keller-Sarmiento, M. I., Etchegoyen, G. S., Pereyra, E. N., \& Chuluyan, H. E. (1987). Neuroendocrine integrative mechanisms in mammalian pineal gland: effects of steroid and adenohypophysial hormones on melatonin synthesis in vitro. J. Steroid Biochem., 27, 565-571.

Chakraborty, S. (1981). Cytology of pineal gland and its response to epinephrine and 6-hydroxydopamine in Indian weaver bird (Ploceus philippinus). Mikroskopie, 38, 187-192.

Chakraborty, S. (1993). A comparitive study of annual changes in pineal gland morphology with reference to the influence of melatonin on testicular activity in Tropical birds, Psittacula cyanocephala and Ploceus philippinus. Gen. Comp. Endocrinol., 92, 71-79.

Chakraborty, S. (1994). Exogenous melatonin act as a reproductive phase dependent modulator of the relationship in morphology between pineal and adrenal cortex in male Blossom headed parakeet (Psittacula cyanocephala) and Indian weaver bird (Ploceus philippinus). Biol. Rhythm Res., 25, 121-132.

Chakraborty, S., \& Maiti, B. R. (1981). Influence of prolactin on pineal gland activity in chicks. Gen. Comp. Endocrinol., 44, 226-229.

Chakraborty, S., Sahu, A., \& Ghosh, A. (1981). Cellular responses of the pineal gland to sex steroids in Bandicoot rat. Mikroscopie, 38, 256-261.

Chakraborty, S., Ghosh, P. R., \& Maiti, B. R. (1982). Cytophysiological responses of the pineal gland to internale aggression in a wild rat. Endokrinologie, 80, 353-356.

Chakraborty, S., Chattapadhyay, S., \& Bandyopadhyay, R. (1994). Testosterone and prolactin effects on pinealocyte nuclei from migratory, Red headed bunting - a comparison with testicular weight. Eur. Arch. Biol., 105, 13-17.

Chaudhuri, S., \& Maiti, B. R. (1988). Pineal activity during the seasonal gonadal cycle in a wild avian species, the treepie (Dendrocitta vagabunda). Gen. Comp. Endocrinol., 76, 346-349.

Chester Jones, I. (1957). 'The Adrenal Cortex'. Univ. Press, Cambridge.

Clausen, F. W., \& Freudenberger, C. B. (1939). A comparison of the effects of male and female sex hormones on immature female rats. Endocrinology, 25, 585-592.

Clementi, R., Fraschini, F., Miller, E., \& Zanoboni, A. (1965). The pineal gland and the control of electrolyte balance and of gonadotrophic secretion: functional and morphological observations. Progr. Brain Res., 10, 585-603.

Diehl, B. J. M., Heidbuchel, U., Welker, H. A., \& Vollrath I. (1984). Day / night changes of pineal gland volume and pinealocyte nuclear size assessed for consequtive days. J. Neural Transm., 60, 19-29. 
Furr, B. J. A., Patterson, J. S., Richardson, D., Slater, S. R., \& Wakeling, A. E. (1979). In M. E. Goldberg (Ed.) Pharmacological and Biochemical properties of drug substances (Vol. 2, pp. 355-399), Washington, APA.

Gromoll, J., Weinbaur, G. F., Simoni, M., \& Nieschlag, E. (1993). Effects of antiandrogen and ethane dimethylsulphonate (EDS) on gene expression, free subunits, bioactivity and secretion of pituitary gonadotrophins in male rats. Mol. Cell Endocrinol., 91, 119-125.

Gusek, W. (1971). The influence of an antiandrogen (cyproterone acetate) on the morphology of the pineal body. Acta Endocrinol. (Kbh.) (Suppl.) 152, 37.

Gusek, W. (1976). Die fienstructur der rattenzirbel und ihr nerhatten untereinfluss von antiandrogen und mach kastration. Endokrinologie, 67, 129-151.

Harper, M. J. K., \& Walpole, A. L. (1967). A new derivative of triphenylethylene : effect on implantation and mode of actin in rats. J. Reprod. Fert., 13, 109-119.

Hernandez, G., Abreu, P., Alonso, R., Santana, C., Moujir, F., \& Calzadilla C. H. (1990). Castration reduces the nocturnal rise of melatonin levels in the male rat by implanting its noradrenergic input. J. Neuroendocrinol., 2, $777-782$.

Hira, Y., Sakai, Y., \& Matsushima S. (1989). Comparisons of sizes of pinealocytes nuclei, and pinealocytes in young and adult Chinese hamsters (Cricetulus griseus) under different photoperiod conditions. J. Pineal Res., 7, 411-418.

Houssay, A. B., \& Barcelo A. C. (1972). Effects of estrogens and progesterone upon the biosynthesis of melatonin by the pineal gland. Experimentia, 28, 478-479.

Issacson, W. K., Jones, S. J., \& Krueger, R. J. (1993). Testosterone, dihydrotestosterone, trenbolone acetate and zeranol alter and synthesis of cortisol in bovine adrenocortical cells. J. Anim. Sci., 71, 1771-1777.

Karasek, M., Rawlikowski, M., Kappers, J. A., \& Stephen, I. I. (1976a). Influence of castration followed by administration of LH-RH on the ultrastructure of rat pinealocytes. Cell Tissue Res., 167, 325-339.

Karasek, M., Rawlikowski, M., Pevet, P., \& Stephen, I. I. (1976b). Ultrastructural and fluorescence histochemical studies of rat pineal gland after castration. Ann. Med. Sect. Pol. Acad. Sci., 21, 1-2.

Kime, D. E., Vinson, G. P., Major, P. W., \& Kilpatrick, R. (1980). Adrenal-gonad relationships. In I. Chester Jones, I. W. Henderson (Eds.), General, Comparative and Clinical Endocrinology of the Adrenal Cortex (Vol. 3, pp. 183-264). New York: Academic Press.

Kitay, J. I. (1963a). Effects of stilbesterol on pituitary-adrenal function in male and female rats. Proc. Soc. Exp. Biol. Med., 112, 679-683.

Kitay, J. I. (1963b). Effects of testosterone on pituitary corticotrophin and adrenal steroid secretion in male and female rats. Acta Endocrinol. (Copenh.), 43, 601-608.

Kitay J. I. (1963c). Pituitary-adrenal function in rat after gonadectomy and gonadal hormone replacement. Endocrinology, 73, 253-260.

Kitay, J. I., Coyne, M. D., Nelson, R., \& Newsom, W. (1966). Relation of the testis to adrenal enzyme activity and adrenal corticosterone production in rat. Endocrinology, 78, 1061-1066.

Koseki, Y., David, T. Z., Chamnees, G.C., \& McGuire, W. L. (1977). Estrogen receptor translocation and replenishment by the antiestrogen tamoxifen. Endocrinology, 101, 1104.

Llaurado, J. G., Claus, J. L., \& Trunnell, J. B. (1962). Aldosterone secretion in faeces of rts treated with estradiol. Endocrinology, 71, 598-604.

Luboshitzky, R., Dharan, M., Goldman, D., Herer, P., Hiss, Y., \& Lavie, P. (1997). Seasonal variation of gonadotrophins and gonadal steroid receptors in human pineal gland. Brain Res. Bull., 44, 665-670.

Maiti, B. R., \& Chakraborty, S. (1980). The mitogenic action of Prolactin on some endocrine organs of chicks. Arch. histol. jap., 43, 341-346.

Maiti, B. R., \& Chakraborty S. (1982). Cytophysiological responses of the pineal gland to long-term administration of norethisterone (a progestogen only contraceptine) in rats. Endokrinologie, 80, 375-378.

Maitra, S. K. (1987). Histophysiological changes in the adrenal cortex of male Blossomheaded parakeet in relation to the annual testicular and environment cycle. J. Interdiscipt. Cycle Res., 17, 213-223. 
Maitra, S. K., \& Chakraborty, S. (1983). Impact of sympatholytic drug (6-OH DA) on osmotic stress induced changes in adrenocorticomedullary system of blossom headed parakeet (Psittacula cyanocephala). Arch. Biol. (Bruxelles), 94, 385-398.

Martinez Soriano, F., Ochando, R., De Tejada, T. H. G., \& Cimas, C. (1990). The effects of soft laser (He-Ne) irradiatin on pineal parenchyma, ultrastructural and pinealocyte caryometric modifications. J. Hirnforsch., 31, 289-296.

Mckerns, W., Coulomb, B., Maletia, E., \& De Renzo, E. C. (1958). Some effects of in vivo administered estrogens on glucose metabolism and adrenal cortical secretion in vitro. Endocrinology, 63, 709-722.

Miller, R. A. (1954). Quantitative changes in the nucleolus and nucleus as indices of adrenal cortical secretory activity. Am. J. Anat., 95, 497-522.

Mizobe, F., \& Furokawa, M. (1976). Enhancement of hydroxyindole-o-methyl-transferase and DNA dependent RNA polymerase activities induced by estradiol in rat pineals in culture. Eur. J. Biochem., 66, 193-199.

Nagle, C. A., Neuspiller, N. R., Cardinali, D. P., \& Rosner, J. M. (1972). Uptake and effect of 17ß-estradiol on pineal hydroxyindole-o-methyltransferase (HIOMT) activity. Life Sci., 12, 1109-1116.

Nagle, C. A., Cardinali, D. P., \& Rosner, J. M. (1974). Effects of castration and testosterone administration on pineal and retinal hydroxyindole-o-methyl transferases of male rats. Neuroendocrinology, 14, 14-23.

Nathanson, I. T., \& Bruesa, A. M. (1941). Effect of testosterone propionate upon the mitotic activity of the adrenals in the intact immature female rats. Endocrinology, 29, 397-401.

Nir, I., Kaiser, N., Hirshmann, N., \& Sulman, F. G. (1970). The effect of $17 \beta$ estradiol on pineal metabolism. Life Sci., 9, 851-858.

Nussdorfer, G. G. (1986). Cytophysiology of the adrenal cortex. In G. H. Bowme, J. F. Danidli (Eds.) International Review of Cytology, (Vol. 98, pp. 79-179). Academic Press, Inc.

Okatani, Y., Watanabe, K., Morioka, N., Hayashi, K., \& Sagara, Y. (1997). Nocturnal changes in pineal melatonin synthesis during puberty : relation to estrogen and progesterone levels in female rats. J. Pineal Res., $22,33-41$.

Okatani, Y., Hayashi, K., Watanabe, K., Morioka, N., \& Sagara, Y. (1998a). Effect of estrogen on melatonin synthesis in female peripubertal rats as related to adenylate cyclase activity. J. Pineal Res., 25, 245-250.

Okatani, Y., Hayashi, K., Watanabe, K., Morioka, N., \& Sagara, Y. (1998b). Effect of estrogen on melatonin synthesis in female peripubertal rats. J. Pineal Res., 24, 67-72.

Quay, W. B. (1976). Seasonal cycle and physiologic correlates of pinealocyte nuclear and nucleolar diameters in the bats, Myotis lucifugus and Myotis sodalis. Gen. Comp. Endocrinol., 29, 369-375.

Quay, W. B., \& Levine, B. E. (1957). Pineal growth and mitotic activity in the rat and the effects of colchicines and sex hormones. Anat. Rec., 129, 65-77.

Rastogi, R. K., \& Chieffi, G. (1975). The effects of antiandrogens and antiestrogens in nonmammalian vertebrates. Gen. Comp. Endocrinol., 26, 79-91.

Reiter, R. J., Trakulrungsi, W. K., Trakulrungsi, C., Vriend, J., Morgan, W. W., Vaughan, M. K., Johnson, L. Y., \& Richardson, B. A. (1982). Pineal melatonin production endocrine and age effects. In D. C. Klein (Ed.), Melatonin rhythm generating system, (pp. 143-154). Karger, Basel.

Roy, S., \& Mahesh, V. B. (1964). Changes in steroid content of the adrenal of rats following prolonged administration of testosterone propionate with or without ACTH. Endocrinology, 74, 187-192.

Sahu, A., \& Chakraborty, S. (1983). Pineal cytology during estrouscycle of wild Bandicoot rat, Bandicota bengalensis. Arch. Biol. (Bruxelles), 94, 399-411.

Sahu, A., \& Chakraborty, S. (1986). Estradiol modulation of pineal gland activity in the wild bandicoot rat, Bandicota bengalensis. Acta Anat., 125, 1-5.

Seyle, H., \& Albert, S. (1942). Age factor in responsiveness of pituitary and adrenals to folliculoids. Prof. Soc. Exper. Biol. Med., 50, 159-161.

Stadtler, F. A., \& Langner, V. (1985). The effect of cyproterone and gonadotrophins on the adrenal gland of juvenile and adult rats. A morphological and morphometrical study. Pathol. Res. Pract., 179, 493-498. 
Tepperman, J., Engel, F. L., \& Long, C. N. H. (1943). A review of adrenal cortical hypertrophy. Endocrinology, $32,373-402$.

Troop, R. C., \& Possanza, G. J. (1962). Gonadal influences on the pituitary adrenal axis. Arch. Biochem., 98, 444-449.

Urry, R. L., Dougherty, K. A., Frehn, J. L., \& Ellis, L. C. (1976). Factors other than light affecting the pineal gland: hypophysectomy, testosterone, dihydrotestosterone, estradiol, cryptorchidism and stress. Amer. Zool., 16, 79-91.

Winer, B. J. (1971). Statistical principle in experimental design. (2nd ed.). New York: Mc Graw Hill.

Wurtman, R. J., Axelrod J., Synder S. H., \& Chu, E. W. (1965). Changes in the enzymatic synthesis of melatonin in the pineal gland during the estrous cycle. Endocrinology, 76, 798-800.

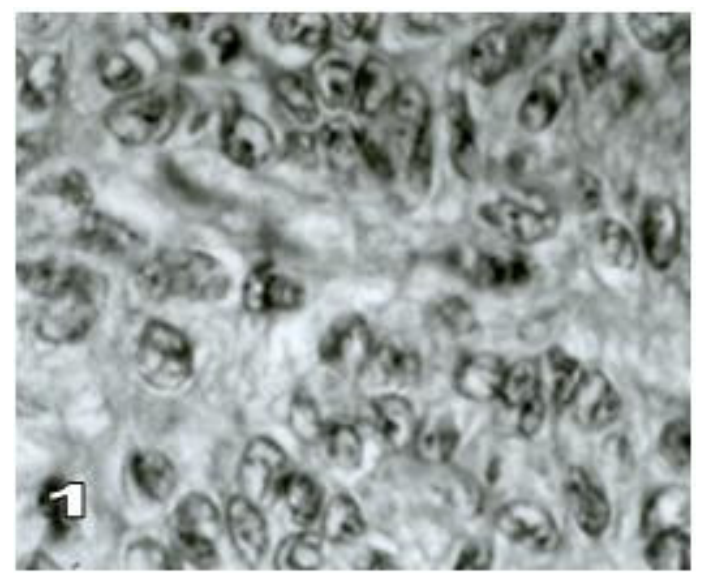

Figure 1. Microphotograph of pineal gland section from control male mice. Nuclei are of a moderate size. X 320

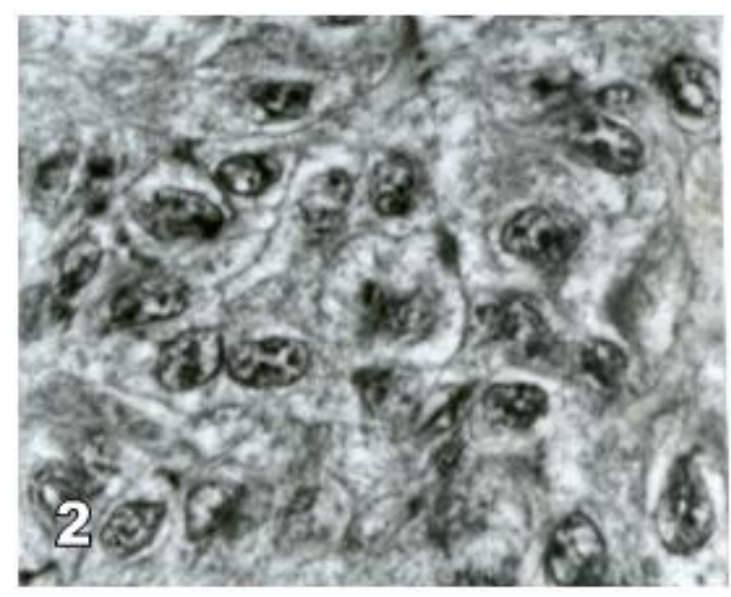

Figure 2. Microphotograph of pineal gland section from estradiol treated male mice. Note the increase in nuclear diameter. X 320 


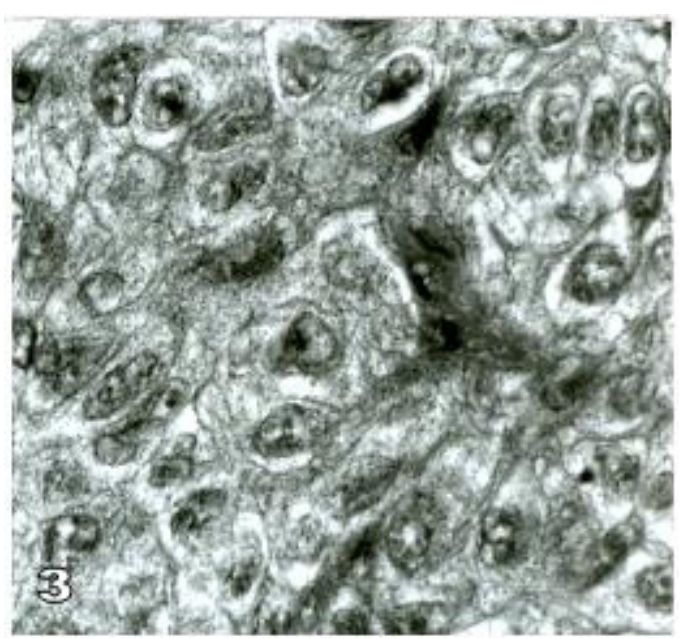

Figure 3. Photomicrograph of pineal gland section from tamoxifen treated male mice showing an increase in nuclear diameter. X 320

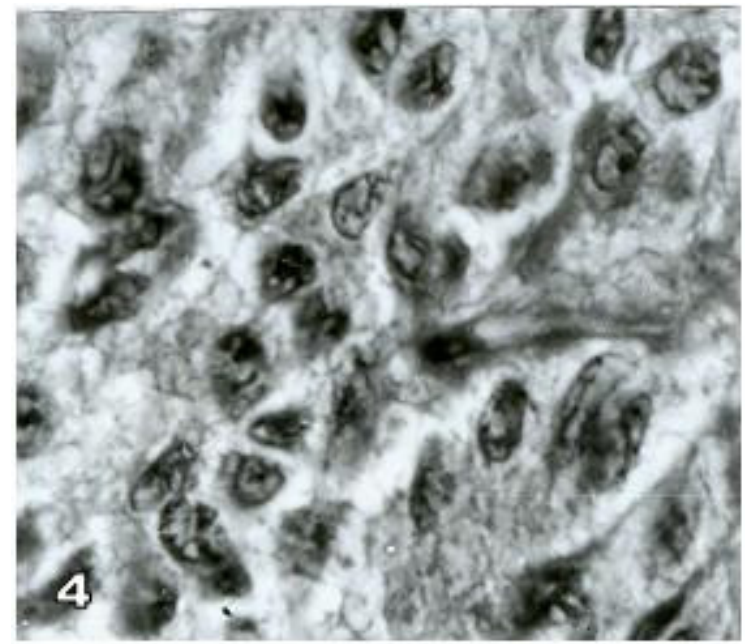

Figure 4. Microphotograph of pineal gland section from testosterone treated male mice showing a decrease in nuclear diameter. X 320

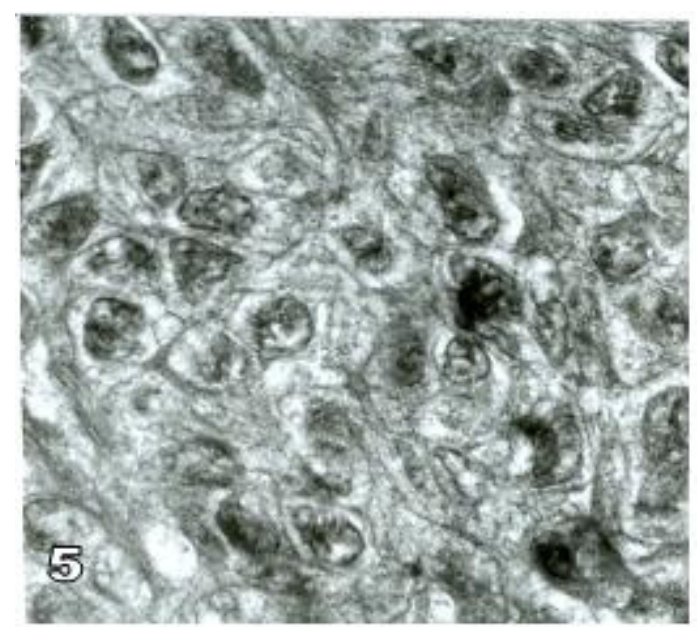

Figure 5. Microphotograph of pineal gland section from flutamide treated male mice. Note the increase in nuclear diameter. X 320 


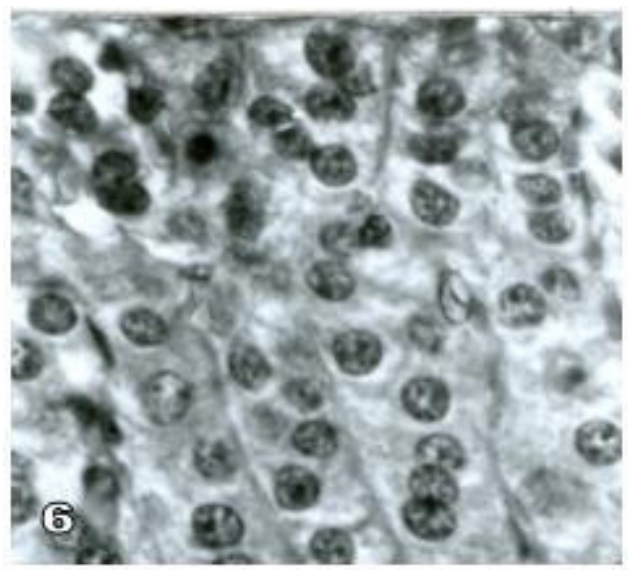

Figure 6. Microphotograph of adrenal cortical section from control male mice showing moderate sized nuclei. X 320

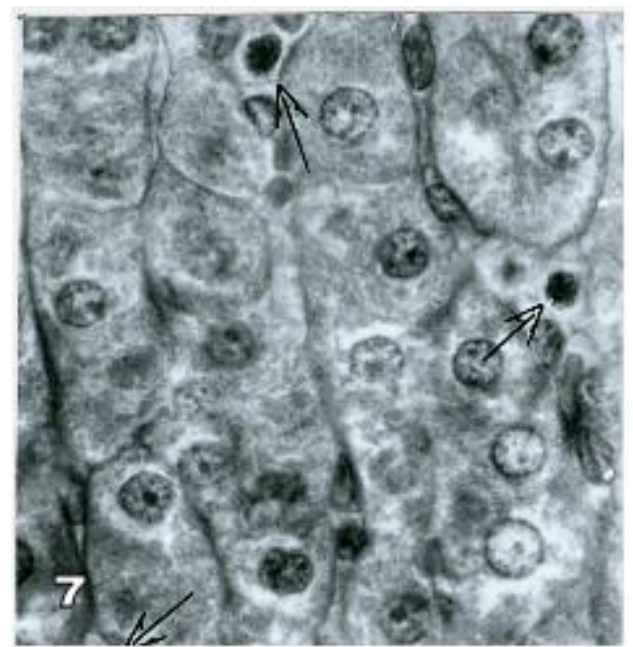

Figure 7. Microphotograph of adrenal cortical section from estradiol treated male mice. Note the increase in nuclear diameter and mitotic figures (arrows). X 320

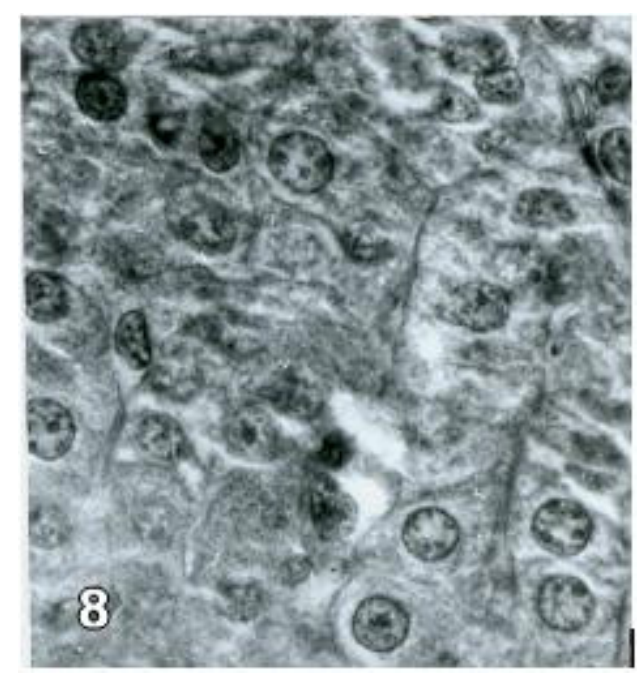

Figure 8. Microphotogrph of adrenal cortex section from tamoxifen treated male mice, showing an increase in nuclear diameter. X 320 


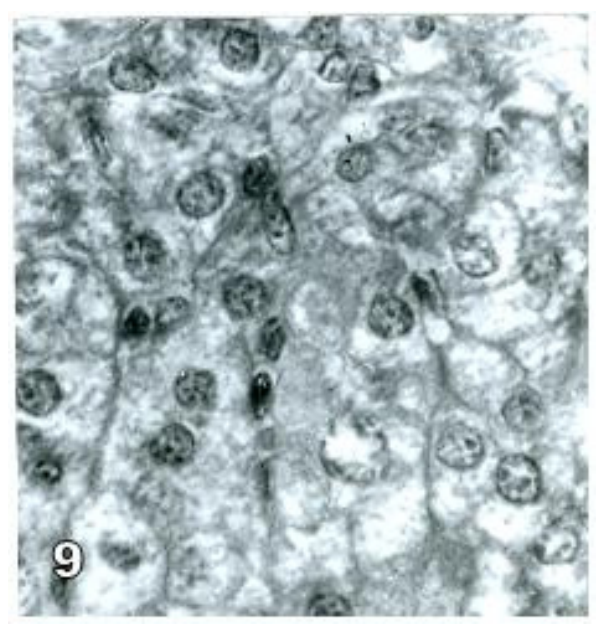

Figure 9. Microphotograph of adrenal cortex section from testosterone treated male mice showing reduced nuclear diameter. X 320

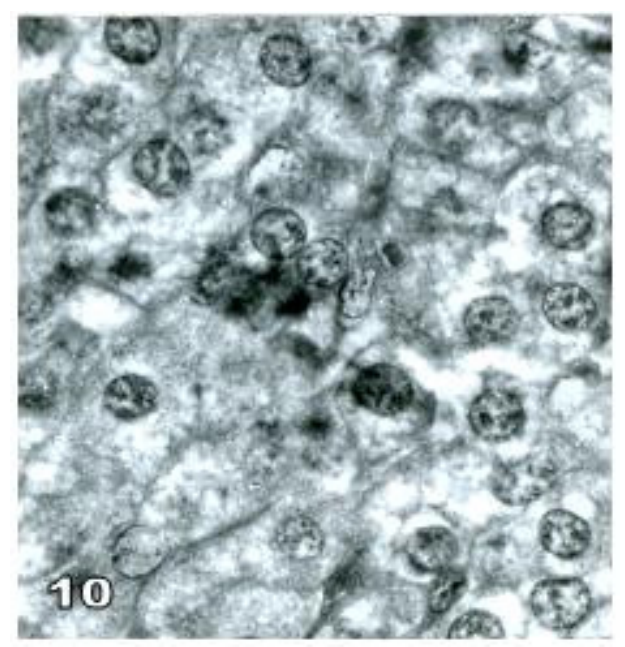

Figure 10. Microphotograph of adrenal cortex section from flutamide treated male mice showing large, round nuclei. X 320

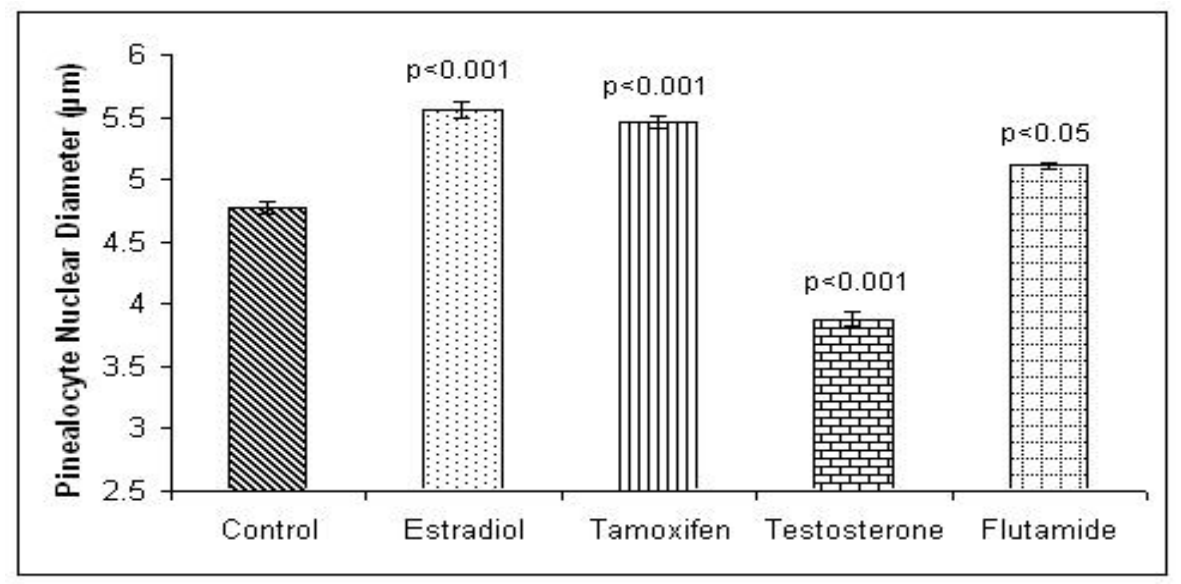

Figure 11. A histogram showing effects of different sex steroid hormones (estradiol, testosterone) and antihormones (tamoxifen, flutamide) on pinealocyte nuclear diameter $(\mu \mathrm{m})$ compared to control values. Estradiol, tamoxifen and flutamide increased nuclear size whereas testosterone decreased nuclear size. Mean values \pm SEM 


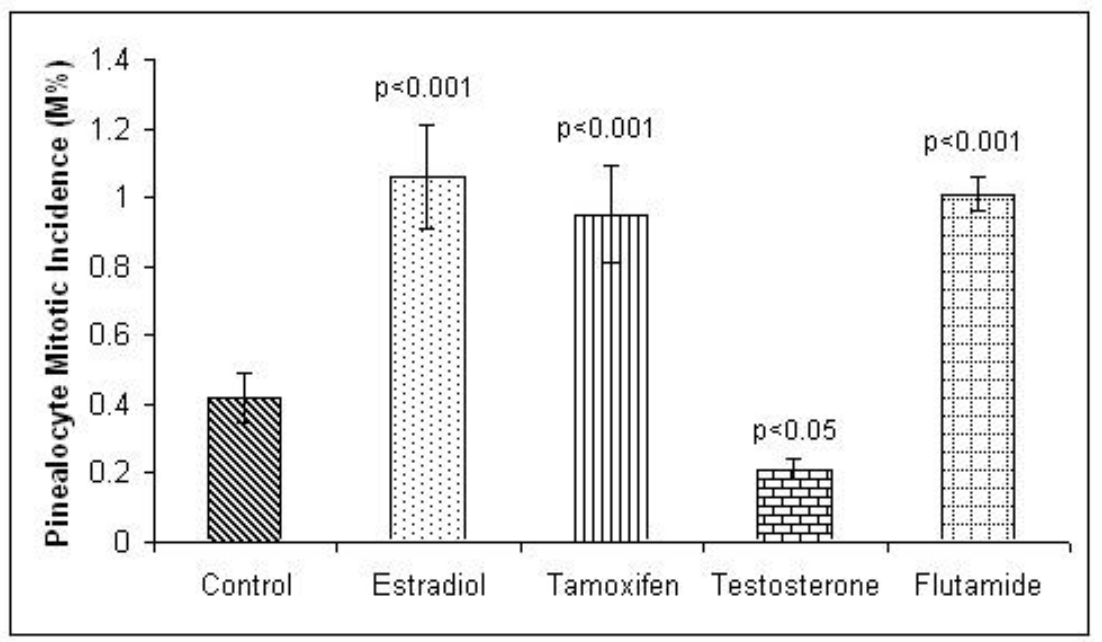

Figure 12. Comparison of the effects of sex steroid hormone (estradiol, testosterone) and antihormone (tamoxifen, flutamide) treatment with respect to pinealocyte mitotic incidence (M\%). Estradiol, tamoxifen and flutamide significantly enhanced mitosis whereas testosterone significantly reduced mitotic events. Values = Mean \pm SEM.

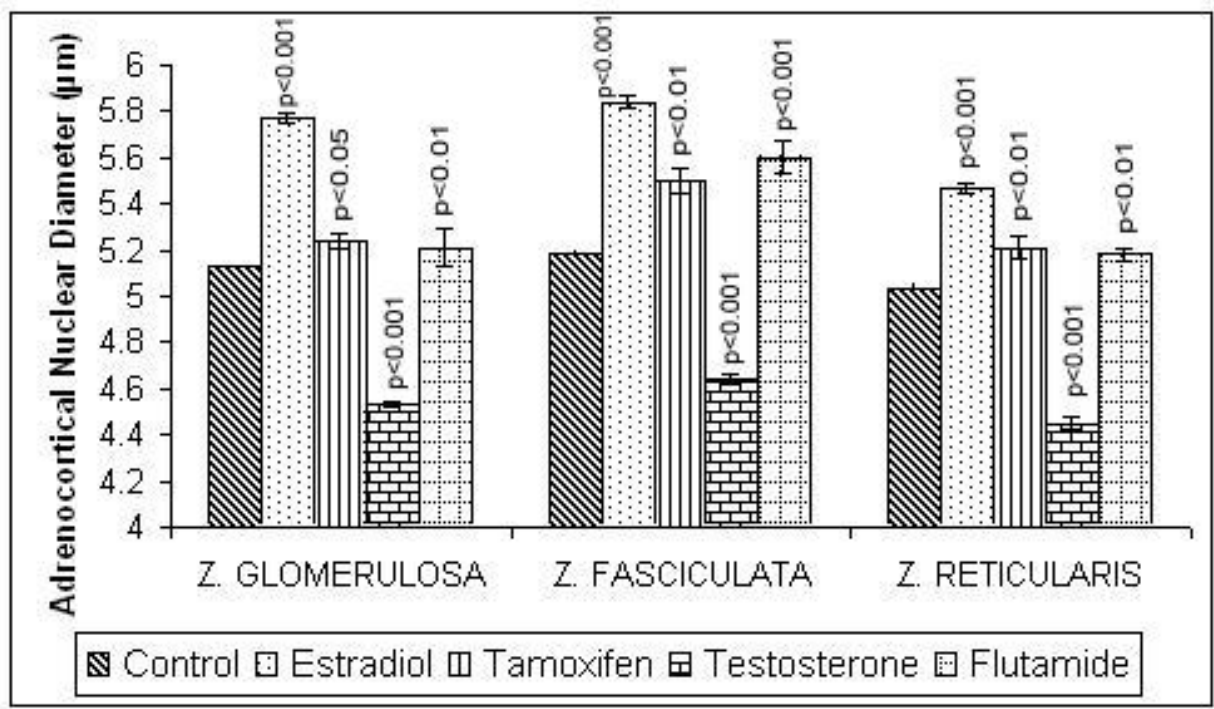

Figure 13. Comparison between control, sex steroid (estradiol, testosterone) and antihormone (tamoxifen, flutamide) treatments of male mice with respect to adrenocortical nuclear diameter $(\mu \mathrm{m})$ of zona glomerulosa, zona fasciculata and zona reticularis. Compared to the control group, estradiol, tamoxifen and flutamide significantly increased nuclear diameter in all the three zones. Testosterone treatment significantly reduced nuclear diameter of all the three zones compared to the control. Values $=$ Mean $\pm \mathrm{SEM}$. 


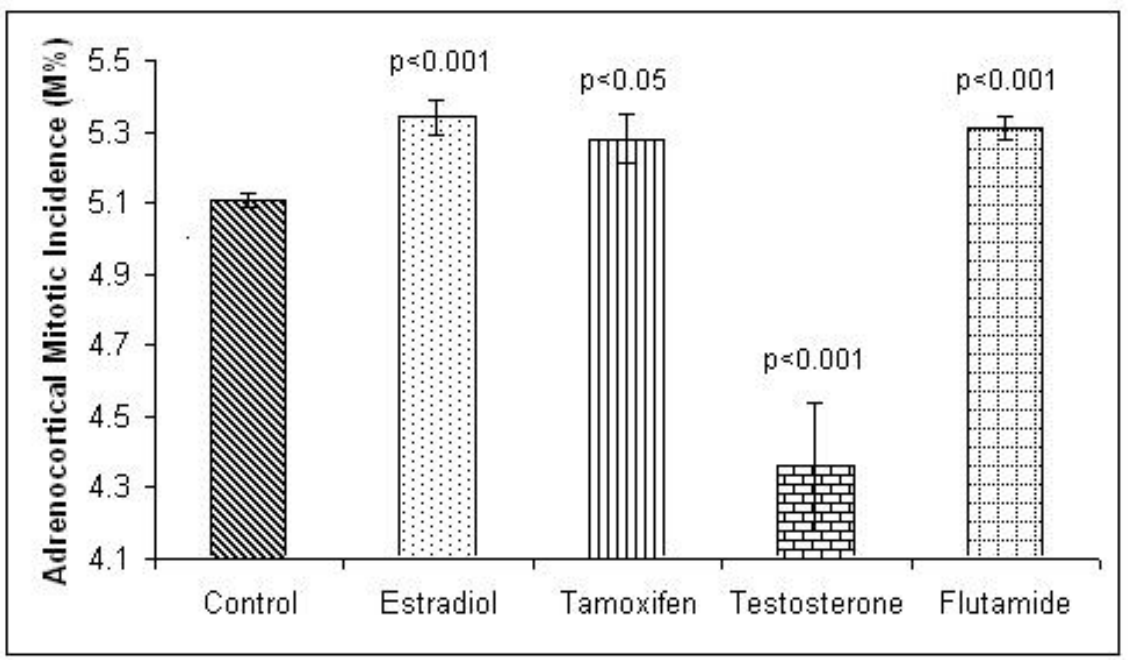

Figure 14. Comparison of the effect of sex steroid (estradiol, testosterone) and antihormone (tamoxifen, flutamide) treatment of male mice on their adrenocortical mitotic incidence ( $\mathrm{M} \%)$ with control groups. Sex steroids and antihormones significantly increased the frequency of mitosis, whereas testosterone reduced mitotic events. $($ Values $=$ Mean \pm SEM $)$ 